\title{
Kajian tingkat kenyamanan berdasarkan termal humidity index (THI) lanskap Jalan Soekarno Hatta Kota Malang
}

\author{
Rizki Alfian ${ }^{1 *}$ dan Nuraini ${ }^{1}$ \\ 1. Program Studi Arsitektur Lanskap, Fakultas Pertanian, Universitas Tribhuwana Tunggadewi Malang \\ *E-mail: rizkialfian87@gmail.com
}

\begin{abstract}
Study of the Comfort Level Based on Thermal Humidity Index (THI) of Soekarno Hatta Streetscape in Malang City. Streets as part of the city's landscape that support the function and activities of the city. Each street in the city area has a streetscape that aims to support the users activities. Soekarno Hatta street is one of the protocol street in Malang city which is quite famous and one of the crowded route in Malang City. This research aims to: 1) To identify vegetation on the streetscape on Soekarno Hatta street; 2) To analyze thermal comfort on the Soekarno-Hatta streetscape. Based on the observation, it is known that the trembesi population dominates at the Soekarno Hatta streetscape. Soekarno Hatta street has an average temperature of $31.1^{\circ} \mathrm{C}$ and an average humidity of $57 \%$. Soekarno Hatta street has THI value of 28.43 whereas THI value which is categorized as comfortable is between 21 - 27. Based on the physical observation on Soekarno Hatta streetscape needs to be done vegetation arrangement because the vegetation in Soekarno Hatta Street has a high density of trees that will interfere with canopy growth when reaching the maximum size. Selection of appropriate shade vegetation and regular maintenance is expected to improve the comfort level in each way. In addition to vegetation, the physical condition of the pedestrian on Soekarno Hatta Road also needs a redesign to support the comfort of pedestrians.
\end{abstract}

Keywords: comfort, Soekarno-Hatta, streetscape , thermal

\section{Pendahuluan}

Lanskap jalan adalah wajah dari karakter lahan atau tapak yang terbentuk pada lingkungan jalan, baik yang terbentuk dari elemen lanskap alami seperti bentuk topografi lahan yang mempunyai panorama yang indah maupun yang terbentuk dari elemen lanskap buatan manusia yang disesuaikan dengan kondisi lahannya. Lanskap jalan mempunyai ciri-ciri yang khas karena harus disesuaikan dengan persyaratan geometrik jalan dan diperuntukkan terutama bagi kenyamanan pengguna serta diusahakan untuk menciptakan lingkungan jalan yang indah, nyaman, dan memenuhi fungsi keselamatan (Direktorat Jenderal Bina Marga, 2010). Menurut Simonds (1983), lanskap jalan berperan penting dalam membangun karakter lingkungan, spasial, dan visual agar dapat memberikan suatu identitas perkotaan.

Salah satu elemen utama pada lanskap jalan selain hardscape juga terdapat softscape yang terdiri dari komposisi vegetasi jalan. Vegetasi jalan merupakan bagian dari ruang terbuka hijau yang berupa jalur untuk menempatkan tanaman serta elemen lanskap lainnya yang terletak didalam Daerah Milik Jalan (Damija) maupun Daerah Pengawasan Jalan (Dawasja). Dengan adanya jalur hijau maka dapat mengurangi dominasi perkerasan yang terdiri dari aspal dan beton. Pada skala kota ruang terbuka hijau diharapkan dapat berfungsi sebagai pengatur iklim mikro, habitat dan rute migrasi satwa, dan toleran terhadap aktifitas perkotaan (Jim et al 2003). Interaksi suatu area dengan objek-objek pada lanskap dapat menciptakan iklim mikro. Interaksi ini berdampak pada suhu udara, kecepatan angin, radiasi matahari, kelembaban relatif dan lainnya. Iklim mikro sangat mempengaruhi kenyamanan termal manusia pada lanskap dan berdampak pada kondisi iklim dalam lanskap. Kombinasi tanaman pohon dan semak berpengaruh signifikan terhadap penurunan suhu. Fungsi kanopi sebagai peneduh dan ground cover sebagai penyerap panas menunjukkan efek yang signifikan terhadap penurunan suhu. Pada daerah penghijauan rata-rata lebih dingin $1^{\circ} \mathrm{C}$ (Bowler et al 2010 dalam alfian 2015).

Menurut Laurie (1986) dalam Rahmiati (2009), standar kelembaban bagi kenyamanan manusia dalam beraktivitas berkisar antara $40 \%$ - 70\% dengan temperature antara $15^{\circ} \mathrm{C}-27^{\circ} \mathrm{C}$ dan Diena (2009) dalam Hadi (2012), menyatakan bahwa indeks kenyamanan dalam kondisi nyaman ideal bagi manusia Indonesia berada pada kisaran THI (Temperature Human Index) dengan nilai 20-26.

Setiap jalan raya di kawasan kota memiliki lanskap jalan yang bertujuan mendukung aktivitas pengguna jalan. Jalan Soekarno Hatta merupakan salah satu jalan protokol di Kota Malang dengan wilayah jalur yang cukup terkenal dan merupakan salah satu jalur yang cukup ramai di Kota Malang. Penelitian ini 
bertujuan untuk; 1) mengidentifikasi vegetasi pada lanskap jalan di Jalan Soekarno Hatta, 2) menganalisis kenyamanan termal pada lanskap Jalan Soekarno-Hatta.

\section{Metode Penelitian}

Metode yang digunakan dalam penelitian ini merupakan metode kuantitatif dengan tahapan teknis sebagai berikut:

1. Tahap Persiapan (Prasurvei)

Tahap persiapan merupakan tahan penentuan lokasi dan persiapan alat dan bahan. Dari tahap ini ditentukan lokasi penelitian yaitu Jalan Raya Soekarno Hatta yang merupakan jalan protokol dan salah satu jalan teraktif di Kota Malang. Peneliti selanjutnya melakukan proses perizinan kepada dinas yang berwenang yaitu Dinas Pekerjaan Umum dan Dinas Kebersihan dan Pertamanan Kota Malang.

\section{Tahap Survei}

Pada tahap ini dilakukan pengamatan dan pengumpulan data suhu udara dan kelembaban secara langsung di lapang. Pengambilan data dilakukan dengan mengukur suhu dan kelembaban dengan jarak titik pengamatan 50 meter. titik pengukuran suhu dan kelembaban terjadi pada ambang pengaman jalan dan median jalan yang dimana di dalamnya terdapat tanaman dan perkerasan. Pengambilan data dilakukan tiga kali dalam satu hari yaitu pada pukul 06.00, 12.00, 17.00, selama tiga hari. Pengambilan data suhu udara dan kelembaban dilakukan hanya pada saat cuaca cerah dengan menggunakan termohygrometer digital.

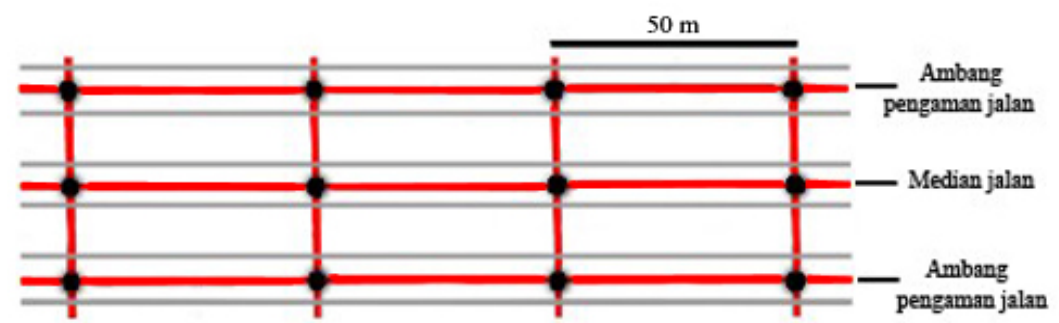

Gambar 1. Ilustrasi Pengambilan Titik Pengamatan Suhu Dan Kelembaban Pada Lanskap Jalan Soekarno Hatta

Pengambilan data berupa ukuran jalan, struktur jalan, tata guna lahan di dapat dari berbagai artikel media cetak dan perpustakaan, serta hasil studi, laporan dan standard peraturan-peraturan dari dinas terkait, pengambilan data jenis vegetasi dan jarak tanam di dapat melalui survey yaitu teknik pengukuran, dokumentasi dan pendataan kondisi eksisting

Tabel 1. Jenis dan Sumber data

\begin{tabular}{lll}
\hline \multicolumn{1}{c}{ Data } & Jenis Data & \multicolumn{1}{c}{ Sumber } \\
\hline Suhu dan Kelembapan & Primer & Data lapang \\
Ukuran Jalan, Struktur Jalan & Primer dan Sekunder & Dinas PU dan Data lapang \\
Tata guna lahan & sekunder & Dinas PU \\
Vegetasi; Jenis dan Jarak Tanam & Primer & Data lapang dan DKP \\
\hline
\end{tabular}

3. Tahap Analisis

Metode yang digunakan analisis indeks kenyamanan adalah pendekatan THI. Pada metode ini, data suhu dan kelembaban yang diperoleh dari hasil pengukuran kemudian dihitung nilai THI dengan rumus;

$$
T H I=0,8 T+(R H \times T) / 500
$$

Keterangan:

$$
\begin{array}{ll}
\mathrm{THI} & =\text { temperature humidity index } \\
\mathrm{T} & =\text { suhu atau temperatur udara }\left({ }^{\circ} \mathrm{C}\right) \\
\mathrm{RH} & =\text { kelembaban udara }(\%)
\end{array}
$$

Nilai THI yang didapat dianalisis menggunakan standar dari Laurie (1990) yang menyatakan bahwa lingkungan ideal memiliki suhu udara $27-28^{\circ} \mathrm{C}$ dan kelembaban $40-75 \%$. 


\section{Hasil Dan Pembahasan \\ 3.1 Kondisi Umum}

\subsubsection{Geografis}

Kota Malang adalah sebuah kota yang terletak di Provinsi Jawa Timur, Indonesia. Kota ini terletak pada ketinggian antara 440 - 667m dpl pada posisi $112.06^{\circ}-112.07^{\circ}$ Bujur Timur dan $7.06^{\circ}-8.02^{\circ}$ Lintang Selatan. Malang merupakan kota terbesar kedua di Jawa Timur dan dikenal dengan julukan "Kota Pelajar" dengan dikelilingi gunung-gunung: Gunung Arjuno di sebelah Utara, Gunung Tengger di sebelah Timur, Gunung Kawi di sebelah Barat, dan Gunung Kelud di sebelah Selatan. Kota Malang memiliki luas $110.06 \mathrm{~km} 2$ dengan batas-batas wilayah yaitu (Gambar 2): Untuk batas wilayah Kota Malang yaitu di sebelah utara adalah Kecamatan Singosari dan Kecamatan Karangploso, Kabupaten Malang; di sebelah timur adalah Kecamatan Pakis dan Kecamatan Tumpang, Kabupaten Malang; di sebelah selatan adalah Kecamatan Tajinan dan Kecamatan Pakisaji, Kabupaten Malang; dan di sebelah barat adalah Kecamatan Wagir dan Kecamatan Dau, Kabupaten Malang.

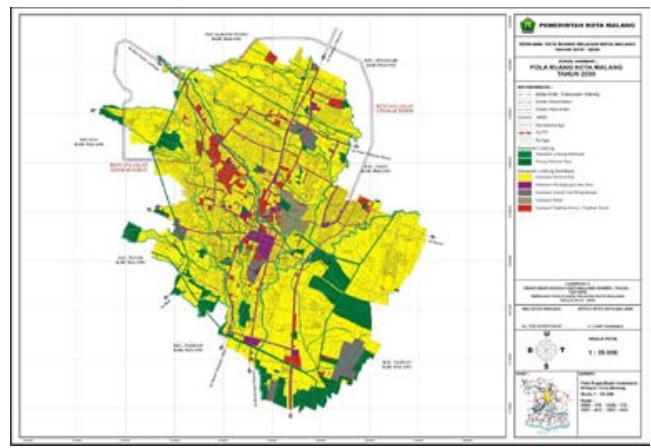

Gambar 2. Master Plan RTH Kota Malang 2012-2032

\subsubsection{Geologi}

Kondisi geologi Kota Malang dapat dibedakan menjadi 4 daerah yaitu daerah endapan gunung api, endapan gunung api Buring, Formasi Welang dan TUF Malang. Sedangkan jenis tanah Kota Malang dapat dibedakan menjadi 4 jenis yaitu tanah alluvial, tanah kambisol, tanah kambisol mediteran, dan tanah latosol (Nugroho 2011). Keadaan tanah di wilayah Kota Malang antara lain di bagian selatan termasuk dataran tinggi yang cukup luas, cocok untuk industri; di bagian utara termasuk dataran tinggi yang subur, cocok untuk pertanian; di bagian timur merupakan dataran tinggi dengan keadaan kurang subur, dan di bagian barat merupakan dataran tinggi yang amat luas menjadi daerah pendidikan. Sedangkan jenis tanah di wilayah Kota Malang ada 4 macam. antara lain alluvial kelabu kehitaman dengan luas 6.930.267 Ha; mediteran coklat dengan luas 1.225.160 Ha; asosiasi latosol coklat kemerahan grey humus dengan luas 1.942.160 $\mathrm{Ha}$; dan asosiasi andosol coklat dan grey humus dengan luas $1.765 .160 \mathrm{Ha}$. Struktur tanah pada umumnya relatif baik, akan tetapi yang perlu mendapatkan perhatian adalah penggunaan jenis tanah andosol yang memiliki sifat peka erosi. Jenis tanah andosol ini terdapat di Kecamatan Lowokwaru dengan relatif kemiringan sekitar 15\%.

\section{$3.1 .3 \mathrm{lklim}$}

Kondisi iklim Kota Malang selama tahun 2012 tercatat rata-rata suhu udara berkisar antara $21.6{ }^{\circ} \mathrm{C}$ sampai $24.7^{\circ} \mathrm{C}$, sedangkan suhu maksimum mencapai $29.5^{\circ} \mathrm{C}$ dan suhu minimum 17.1 ${ }^{\circ} \mathrm{C}$. Rata-rata kelembaban udara berkisar $69 \%$ - 85\% dengan kelembaban maksimum 98\% dan minimum mencapai $28 \%$. Seperti umumnya daerah lain di Indonesia, Kota Malang mengikuti perubahan putaran $2 \mathrm{iklim}$, musim hujan dan musim kemarau. Dari hasil pengamatan Stasiun Klimatologi Karangploso. Curah hujan yang relatif tinggi terjadi pada bulan Februari, Nopember, Desember. Sedangkan pada bulan Juni dan September Curah hujan relatif rendah. Kecepatan angin maksimum terjadi di bulan Mei, September, dan Juli. 


\subsubsection{Tanah dan Topografi}

Daerah Kota Malang dengan ketinggian antara 440 - 667 meter dari permukaan air laut. Penyebaran Daerah wilayah dataran tinggi meliputi daerah kecamatan Klojen, Sukun, Lowokwaru, Blimbing dan Daerah Kecamatan Kedungkandang bagian barat. Tingkat kemiringan di dataran tinggi cukup bervariasi, di beberapa tempat merupakan suatu daerah dataran dengan kemiringan 2 $-5 \%$, sedang dibagian lembah perbukitan rata-rata kemiringan $8-15 \%$. Wilayah dataran tinggi batuannya terdiri dari Alluvial kelabu daerah perbukitan. Daerah berbukitan rendah adalah daerah yang reliefnya relatif datar, dengan beda ketinggian antara $5-25 \mathrm{~m}$, Penyebaran daerah perbukitan wilayah Kota Malang dengan ketinggian antara 500 - $999 \mathrm{~m}$ di atas permukaan air laut yang terdapat di bagian timur Kecamatan Kedungkandang. Jenis tanah di wilayah Kota Malang ialah Alluvial kelabu kehitaman dengan luas 6,930,267 Ha dan relatif kemiringan sekitar 15\%, struktur tanah pada umumnya relatif baik.

\subsubsection{Hidrologi}

Dengan perkembangan suatu wilayah atau kawasan, terutama perkotaan, tidak dapat dihindari adanya pembangunan yang apabila tidak dilaksanakan secara terpadu dan meyeluruh akan mempengaruhi proses-proses alami dalam siklus hirologi yang akhirnya menyebabkan terganggunya, keseimbangan hidrologi.

Dari hasil pengamatan Stasiun Klimatologi Karangploso curah hujan yang relatif tinggi selama tahun 2010 hujan terjadi hampir di setiap bulan curah hujan tertinggi terjadi pada bulan April yaitu mencapai $526 \mathrm{~mm}$, yang terjadi selama 27 hari. Kecepatan angin maksimum terjadi di bulan Mei, September, dan Juli.

\subsection{Jalan Soekarno Hatta}

Jalan Soekarno Hatta merupakan salah satu jalan protokol di Kota Malang dengan wilayah jalur yang cukup terkenal dan merupakan salah satu jalur yang cukup ramai di Kota Malang. Untuk mengurangi tingkat pencemaran polusi udara yang mengbabkan suatu kawasan menjadi tidak nyaman, pemerintah daerah Kota Malang menginginkan penambahan jumlah vegetasi di jalan. Vegetasi yang ada saat ini adalah berupa pohon peneduh dan pohon pengarah.

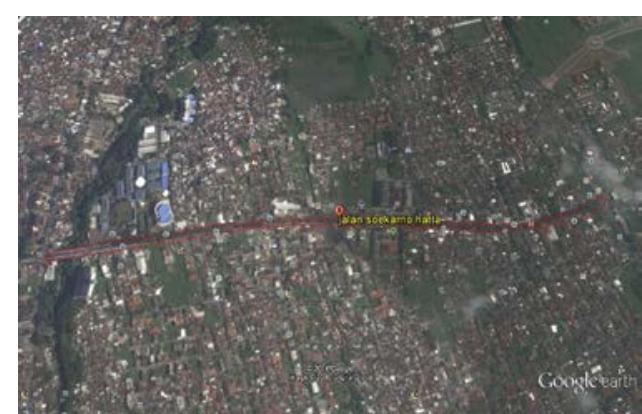

Gambar 3. Peta Jalan Soekarno Hatta (sumber: Google Earth 2017)

Dari hasil pengamatan kondisi hidrologi di Lanskap Jalan Soekarno Hatta sangat baik dan terawat dikarenakan letak hidrologi berada di kedua sisi jalan yaitu sebelah barat dan timur badan jalan denagn ukuran tinggi $100 \mathrm{~cm}$, lebar atas $80 \mathrm{~cm}$ dan lebar bawah $60 \mathrm{~cm}$ dengan sistim drainase tertutup. Secara umum, berdasarkan pengamatan drainase di Lanskap Jalan Soekarno Hatta dapat dilihat pada Gambar 4. 


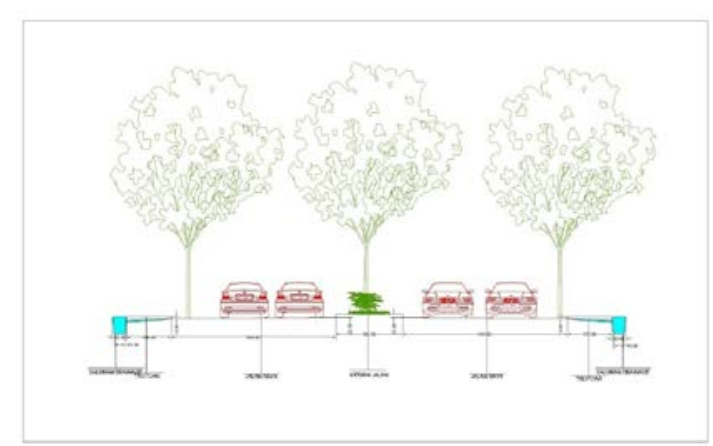

Gambar 4. Pengamatan Hidrologi di Jalan Soekarno Hatta

Pemeliharan tanaman pada Lanskap Jalan Soekarno Hatta, telah memenuhi kriteria penanaman pada lanskap jalan yaitu terdapat tanaman penaung yang cukup. Jumlah tanaman penaung di Jalan Soekarno Hatta yang cukup banyak dan ditanam dengan jarak penanaman yang sesuai sehingga membentuk kanopi antar pohon yang rindang dan ada tanaman penaung yang belum dewasa turut mempengarui iklim mikro.

Berdasarkan hasil pengamatan, Jalan Soekarno Hatta memiliki jenis pohon peneduh berupa pohon trembesi (Samanea saman). Berdasarkan hasil pengamatan diketahui bahwa populasi trembesi mendominasi lanskap Jalan Soekarno Hatta. Saat ini kondisi pohon trembesi sebagian besar belum mencapai ukuran maksimal, terutama pada segmen persimpangan jalan lampu merah hingga bundaran tugu pesawat.

Tabel 2. Beberapa Jenis Vegetasi di Jalan Soekarno Hatta

\begin{tabular}{lll}
\hline Kelompok Tanaman & Nama Tanaman & Nama Latin \\
\hline Pohon & Trembesi & Samanea saman \\
& Palem Phoenix & Phoenix roebelinii O'BrienChrysalidocarpus \\
& Palem Kuning & lutescens \\
Semak & Kamboja & Nerium oleander \\
& Pucuk Merah & Oleinum syzygium \\
Melati Jepang & Pseuderanthemumreticulatum \\
Bunga Sepatu & Hibiscus roso-sinensis \\
& Bunga Bakung & Crinum asiaticum \\
Kaktus & Cereus peruvianus \\
Bogenvil & Bougainvillea glabra \\
& Pandan Afrika & Pandanus pygmeus \\
& Ekor Kucing & Acalypha hispid burm.F. \\
& Bunga Lilin & Pachystachys lutea L. \\
& Krimbosa & Tabernaemontana corymbosa \\
& Teh-tehan & Acalypha siamensis \\
Andong & Cordyline fruticosa \\
Soka & Ixora coccinea \\
& Hujan Emas & Galphimia glauca \\
& Java White & Acalypha wilkesiana \\
Ararea & Osmoxylon lineare variegata \\
Euphorbia & Euphorbia milii \\
Walisongo & Scheffra grandi flora \\
& Nanas Hias & Ananas Comosum Variegates \\
Tricolor & Dracaena marginata 'Tricolor' \\
Drasena & Dracaena draco \\
Rumput Gajah & Pennisetum purpureum \\
Taiwan Beauty'ungu' & Cuphea hyssopifolia \\
Cosandra & Crossandra infundibuliformis \\
Ruellia & Ruelli malacorperma \\
Bunga Telekan & Lantana camara \\
\hline
\end{tabular}




\subsubsection{Iklim Mikro pada Jalan Soekarno Hatta}

Suhu udara rata-rata di Jalan Soekarno Hatta $\left(31,1^{\circ} \mathrm{C}\right)$ dan rata-rata kelembapan $(57 \%)$. Faktorfaktor yang memengaruhi kenyamanan tidak hanya berasal dari suhu udara tetapi juga dari kelembaban, intensitas penyinaran matahari, serta pergerakan udara (angin). Jalan Soekarno Hatta memiliki panjang 1850 Meter, dengan lebar badan jalan 9,40 meter, lebar trotoar 3,60 meter dan lebar median 3,90 meter. Dari pemetaan jalan dengan jarak antartitik 50 meter diperoleh 37 titik pengambilan data suhu udara dan kelembaban.

Lanskap Jalan Soekarno Hatta berdasarkan hasil pengamatan Suhu dan Kelembaban selama tiga hari pengamatan di Jalan Soekarno Hatta diperoleh data sebagai berikut (Gambar 5, 6 dan 7).

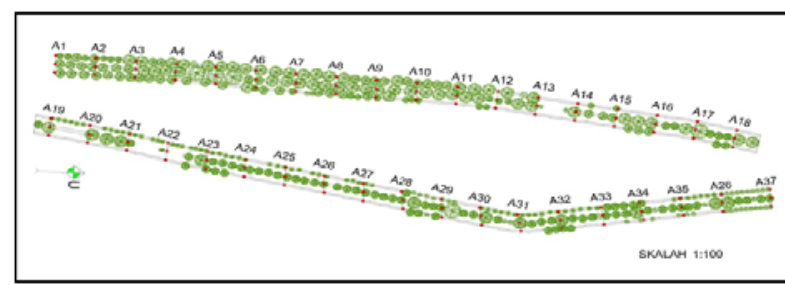

Gambar 5. Titik Pengamatan Suhu di Jalan Soekarno Hatta

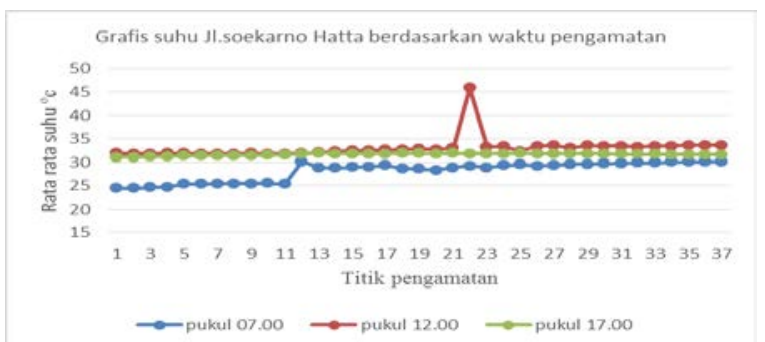

Gambar 6. Grafik Pengamatan Suhu di Jalan Soekarno Hatta

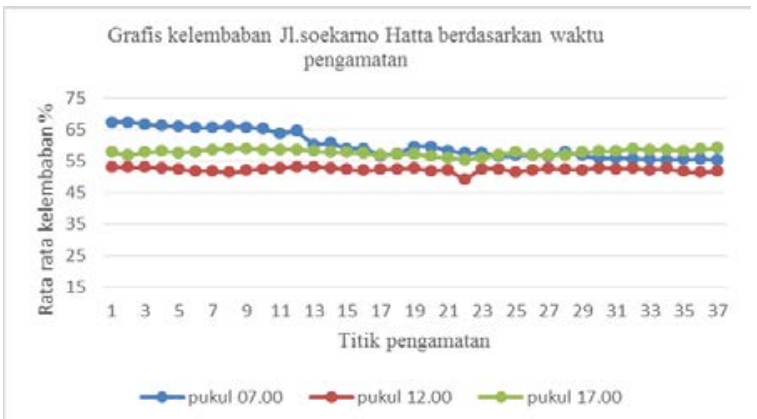

Gambar 7. Grafik Pengamatan Kelembaban di Jalan Soekarno Hatta

Jarak vegetasi di Jalan Soekarno Hatta mempengaruhi suhu udara maupun kelembaban. Pada area jalan yang jarak tanam pohonnya relatif tidak rapat, suhu udara cenderung lebih tinggi dan kelembaban lebih rendah. Sebaliknya pada daerah dengan jarak tanam pohon cukup rapat, suhu udara cenderung lebih rendah dan kelembaban menjadi lebih tinggi selain itu kondisi tajuk pohon-pohon penaung yang ada belum cukup dewasa sehingga kerapatan yang kurang turut mempengaruhi iklim mikro di Jalan Soekarno Hatta. Selain unsur cuaca dan tajuk pohon, lanskap tataguna lahan di sekitar jalan juga turut mempengaruhi suhu udara. Hal ini dikarenakan Fungsi kanopi sebagai peneduh dan ground cover sebagai penyerap panas menunjukkan efek yang signifikan terhadap penurunan suhu. Pada daerah penghijauan rata-rata lebih dingin $1^{\circ} \mathrm{C}$ (Bowler et al 2010 dalam alfian 2015).

Nilai suhu di Jalan Soekarno Hatta berkisar antara $24,48-45,9^{\circ} \mathrm{C}$ dan Nilai kelembaban pada Jalan Soekarno Hatta berkisar dari 49,12-67,33\%. Saat siang hari yang terik pantulan sinar dari perkerasan menjadi faktor yang dapat mengurangi kenyamanan, namun dengan adanya barisan pepohonan peneduh di median jalan mampu memperbaiki iklim mikro dan kenyamanan, serta mengontrol angin. Dominasi pohon yang ditanam yaitu trembesi (Samanea saman) area median jalan. Adanya vegetasi penaung cukup mampu menurunkan suhu udara serta meningkatkan nilai kelembaban. Dengan adanya pohon trembesi (Samanea saman), ukuran tajuk trembesi yang cukup lebar dan sehingga dapat menaungi dan meningkatkan kenyamanan jalan. 
Nilai suhu udara pada Jalan Soekarno Hatta cukup bervariasi. Berdasarkan hasil pengukuran suhu di Jalan Soekarno Hatta, suhu udara tertinggi berada pada titik 22 pukul 12.00 siang. Titik ini berada dekat dengan area persimpangan putar balik arah dan tidak ada pohon sehingga suhu udara menjadi lebih tinggi. Area ini didominasi perkerasan dan jalan berupa aspal. Suhu udara terendah berada pada titik 1-11 pukul 07.00 pagi. Hal ini dipengarui oleh penyinaran matahari yang masih sdikit dan jumlah pohon trembesi yang banyak. Pada titik pengamatan 1 hingga 11 di ketahui pohon trambesi (Samanea saman) ditanam pada bagian barat, timur dan median jalan. Tajuk pohon relatif rapat dan bersinggungan. Hal ini menyebabkan cahaya matahari terhalang masuk sehingga suhunya menjadi lebih rendah. Selain itu, faktor kerapatan tajuk juga meningkatkan kelembaban pada titik pengamatan 1-11, dibandingkan pada titik pengamatan lainya yang memiliki kerapatan tajuk rendah bahkan cenderung terbuka.

Nilai kelembaban pada titik 22 pukul 12.00 siang. memiliki nilai yang rendah karena berupa area terbuka dan tidak ada pohon sehingga sinar matahari langsung mencapai jalan dan menyebabkan tingkat penguapan tinggi serta faktor angin yang memindahkan uap air hasil penguapan

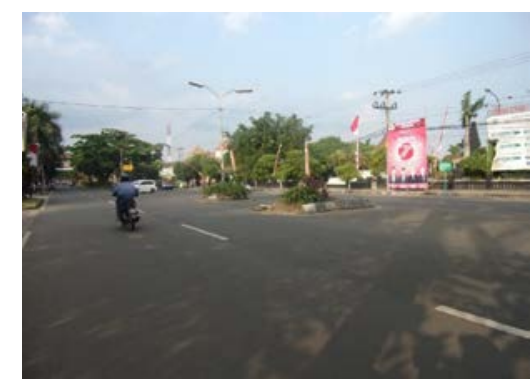

Gambar 8. Pengamatan Titik 22 di Jalan Soekarno Hatta

\subsection{Analisis THI Jalan Soekarno Hatta}

Untuk mengetahui suhu udara dan kelembaban terhadap kenyamanan secara kuantitatif digunakan Temperature Humidity Index (THI). Metode ini menggunakan faktor suhu udara dan kelembaban udara. Tingkat kenyamanan merupakan serangkaian kondisi dari beberapa faktor. Hasil dari beberapa faktor inilah yang memengaruhi nilai THI. Dari hasil perhitungan didapat bahwa nilai THI untuk Jalan Soekarno Hatta (28.43), Nilai THI jalan tersebut berada diluar nilai kenyamanan THI yaitu 21-27. Suhu udara di Jalan Soekarno Hatta berkisar antara $24,48-45,9^{\circ} \mathrm{C}$ dan Nilai kelembaban untuk bagian ini berkisar dari $49.12-$ $67.33 \%$. Laurie (1990) juga menyatakan bahwa iklim ideal bagi manusia adalah suhu udara dengan nilai 27 $28^{\circ} \mathrm{C}$ dan nilai kelembaban $40-75 \%$. Jika dibandingkan dengan hasil pengamatan suhu udara pada jalan Soekarno Hatta, maka jalan tergolong belum memiliki lingkungan yang ideal dan nilai kelembaban setiap jalan tergolong kurang nyaman jika dibandingkan dengan standar Laurie.

Dari hasil THI ini maka perlu dilakukan penataan ulang lanskap jalan terutama dalam penataan vegetasi pada lanskap jalan. Pemilihan jenis vegetasi merupakan faktor utama dalam meningkatkan kualitas fisik dan biofisik pada lanskap jalan. Dari hasil pengamatan suhu terlihat bahwa masih terdapat beberapa titik pengamatan dengan suhu yang tinggi dikarenakan tidak adanya naungan vegetasi pada lokasi tersebut. Hal ini juga telah dijelaskan oleh Carpenter et al (1975) bahwa penempatan pohon di sepanjang jalan dapat memberikan suatu naungan, memberikan kesan, mengarahkan pada suatu objek, menyediakan aset visual dan menciptakan sense of unity and stability.

\subsection{Analisis Hasil Kuisioner Jalan Soekarno Hatta}

Dari hasil penyebaran kuisioner di jalan Soekarno Hatta didapatkan pengguna jalan adalah $53.33 \%$ Laki-laki dan 46.67\% Perempuan. Pendidikan pengguna jalan adalah SMP sebesar 26.67\%, SMA 33.33\%, Perguruan Tinggi 36.67\% dan 3.33\% Dan yang lain lain. Pengguna jalan yang berasal dari Kota Malang sebesar $90 \%$ dan berasal dari luar Kota Malang sebesar 10\%. Intensitas pengguna jalan yang sekedar lewat $40 \%$ dan Intensitas pengguna jalan yang sering lewat $60 \%$. Motivasi yang melewati jalan lokasi jalan nyaman $66.67 \%$, suasana jalan yang tidak macet $20 \%$ dan nilai ektetika dan keindahannya baik $13.33 \%$. Dari hasil penyebaran kuisioner mayoritas pengguna jalan berasal dari Kota Malang. Intensitas pengguna yang sering lewat dengan tingkat pendidikan SMA dan Perguruan Tinggi karena di sepanjang Jalan Soekarno Hatta terdapat banyak Rumah Makan dan Cafe. Selain itu, lokasi Jalan Soekarno Hatta juga dekat dengan beberapa perguruan tinggi, seperti Universitas Brawijaya, Politeknik Negeri Malang, dan Kampus Asia Stimiki. 


\subsubsection{Hubungan Kenyamanan dengan Faktor Jenis Kelamin Responden}

Untuk mengetahui apakah jenis kelamin memengaruhi respon kenyamanan di Jalan Soekarno Hattadigunakan uji chi-square. Untuk mengetahui kaitan antara respon kenyamanan dengan data diri responden, digunakan hipotesis sebagai berikut:

$\mathrm{H}_{0}$ : Kenyamanan jalan tidak berhubungan dengan faktor jenis kelamin $\mathrm{H}_{1}$ : Ada hubungan antara kenyamanan jalan dengan faktor jenis kelamin Chi-tabel $=3,82$; Chi-hitung $=0,37$.

Karena Chi-hitung $(0,37)<$ Chi-tabel $(3,82)$ maka tidak ada hubungan antara kenyamanan pengguna jalan di Jalan Soekarno Hattadengan faktor jenis kelamin pengguna jalan (terima $\mathrm{Ho}$ )

Tabel 7. Deskriptif Data Responden Kenyamanan Berdasarkan Jenis Kelamin

\begin{tabular}{lllll}
\hline No & Pilihan Jawaban & & \multicolumn{2}{c}{ Jenis Kelamin } \\
& & Laki-laki & Perempuan & Jumlah \\
\hline 1 & Nyaman & 12 & 9 & 21 \\
2 & Tidak Nyaman & 4 & 5 & 9 \\
& Jumlah & 16 & 14 & 30 \\
\hline
\end{tabular}

Tabel 7 menunjukkan bahwa 70\% responden (21 responden) merasa nyaman dengan iklim mikro Jalan Soekarno Hatta, diikuti oleh $30 \%$ responden (9 orang) menyatakan tidak nyaman. Proporsi persepsi kenyamanan ditinjau dari jenis kelamin cukup sebanding. Tabel 3 menunjukkan bahwa persentase pendapat rasa nyaman oleh responden laki-laki (75\%) lebih besar dari responden perempuan (64\%).

\subsubsection{Hubungan Kenyamanan dengan Faktor Pendidikan Responden}

Hipotesis untuk hubungan kenyamanan dengan faktor pendidikan responden adalah sebagai berikut:

$H_{0}$ : Kenyamanan jalan tidak berhubungan dengan faktor pendidikan

$\mathrm{H}_{1}$ : Ada hubungan antara kenyamanan jalan dengan faktor pendidikan

Chi-tabel $=7,82$; Chi-hitung $=2,34$

Didapatkan Chi-hitung $<$ Chi-tabel terima $\mathrm{H}_{0}$

Dari perhitungan Chi-square diketahui bahwa tidak ada hubungan antara faktor pendidikan responden terhadap persepsi kenyaman jalan di Jalan Soekarno Hatta. Responden sebagian besar berpendidikan SMP, SMA, Akademik, Perguruan Tinggi dan lainnya. Tabel 8 menunjukkan bahwa persentase pendapat rasa nyaman oleh responden yang pendidikan SMP sebesar (75\%), SMA (70\%), Perguruan Tinggi (64\%), dan $(100 \%)$ dan lainnya.

Tabel 8. Deskriptif Data Responden Kenyamanan Berdasarkan Pendidikan

\begin{tabular}{llllll}
\hline Pilihan Jawaban & & \multicolumn{4}{c}{ Pendidikan } \\
& SMP & SMA & Akademik & Perguruan Tinggi & Jumlah \\
\hline Nyaman & 6 & 7 & - & 7 & 21 \\
Tidak Nyaman & 2 & 3 & - & 4 & 9 \\
Jumlah & 8 & 10 & - & 11 & 30 \\
\hline
\end{tabular}

\subsubsection{Hubungan Kenyamanan dengan Faktor Tempat Tinggal Responden} berikut: Hipotesis untuk hubungan kenyamanan dengan faktor tempat tinggal responden adalah sebagai

$\mathrm{H}_{0}$ : Kenyamanan jalan tidak berhubungan dengan faktor tempat tinggal $\mathrm{H}_{1}$ : Ada hubungan antara kenyamanan jalan dengan faktor tempat tinggal Chi-tabel = 7,82; Chi-hitung = 2,36; didapatkan Chi-hitung $<$ Chi-tabel terima $\mathrm{H}_{0}$

Dari perhitungan diketahui bahwa tempat tinggal responden tidak berhubungan dengan kenyamanan jalan di Jalan Soekarno Hatta. 
Tabel 9. Deskriptif Data Responden Kenyamanan Berdasarkan Tempat Tinggal

\begin{tabular}{clllll}
\hline \multirow{2}{*}{ No } & \multirow{2}{*}{ Pilihan Jawaban } & Kota Malang & Luar Kota Malang & Jumlah \\
\hline 1 & Nyaman & 20 & 1 & 21 \\
2 & Tidak Nyaman & 7 & 2 & 9 \\
& Jumlah & 27 & 3 & 30 \\
\hline
\end{tabular}

Tabel 9 menunjukkan bahwa persentase pendapat rasa nyaman oleh responden yang tinggal di Kota Malang (74\%) lebih besar dari responden yang tinggal di luar Kota Malang (33\%).

\subsubsection{Hubungan Kenyamanan dengan Faktor Intensitas Pengguna Responden}

Hipotesis untuk hubungan kenyamanan dengan faktor Intensitas pengguna responden adalah sebagai berikut:

$\mathrm{H}_{0}$ : Kenyamanan jalan tidak berhubungan dengan faktor intensitas pengguna $\mathrm{H}_{1}$ : Ada hubungan antara kenyamanan jalan dengan faktor intensitas pengguna Chi-tabel $=7,82$; Chi-hitung $=2,31$; didapatkan Chi-hitung $<$ Chi-tabel terima $\mathrm{H}_{0}$ Dari perhitungan diketahui bahwa intensitas pengguna responden tidak berhubungan dengan kenyamanan pengguna jalan di Jalan Soekarno Hatta.

Tabel 10. Deskriptif Data Responden Kenyamanan Berdasarkan Intensitas Pengguna.

\begin{tabular}{lllll}
\hline No & Pilihan Jawaban & \multicolumn{2}{l}{ Intensitas Pengguna } & \\
& & Sekedar Lewat & Sering Lewat & Jumlah \\
\hline 1 & Nyaman & 8 & 14 & 22 \\
2 & Tidak Nyaman & 4 & 4 & 8 \\
& Jumlah & 12 & 18 & 30 \\
\hline
\end{tabular}

Tabel 10 menunjukkan bahwa persentase pendapat rasa nyaman oleh responden yang sekedar lewat (67\%) lebih kecil dari responden yang sering lewat (78\%).

\subsubsection{Hubungan Kenyamanan Dengan Faktor Motivasi Melewati Jalan}

Hipotesis untuk hubungan kenyamanan dengan faktor motivasi melewati jalan responden adalah sebagai berikut:

$\mathrm{H}_{0}$ : Kenyamanan jalan tidak berhubungan dengan faktor motivasi melewati jalan

$\mathrm{H}_{1}$ : Ada hubungan antara kenyamanan jalan dengan faktor motivasi melewati jalan

Chi-tabel = 7,82; Chi-hitung = 2,38; didapatkan Chi-hitung $<$ Chi-tabel terima $\mathrm{H}_{0}$

Dari perhitungan diketahui bahwa motivasi melewati jalan responden tidak berhubungan dengan kenyamanan jalan di Jalan Soekarno Hatta.

Tabel 11. Deskriptif Data Responden Kenyamanan Berdasarkan Motivasi Melewati Jalan

\begin{tabular}{|c|c|c|c|c|c|}
\hline \multirow[t]{2}{*}{ No } & \multirow[t]{2}{*}{ Pilihan Jawaban } & \multicolumn{4}{|c|}{ Motivasi Melewati Jalan } \\
\hline & & $\begin{array}{l}\text { Lokasi Jalannya } \\
\text { Nyaman }\end{array}$ & $\begin{array}{c}\text { Suasana } \\
\text { Jalannya Tidak } \\
\text { Macet }\end{array}$ & $\begin{array}{l}\text { Nilai Estetika dan } \\
\text { Keindahannya Baik }\end{array}$ & Jumlah \\
\hline 1 & Nyaman & 13 & 4 & 4 & 21 \\
\hline 2 & Tidak Nyaman & 8 & 1 & - & 9 \\
\hline & Jumlah & 21 & 5 & 4 & 30 \\
\hline
\end{tabular}

Tabel 11 menunjukkan bahwa persentase pendapat rasa nyaman oleh responden yang menjawab lokasi jalannya Nyaman (62\%) lebih kecil dari responden yang menjawab suasana jalannya tidak macet (80\%) dan responden yang menjawab nilai estetika dan keindahannya baik (100\%).

\section{Simpulan}

Kenyamanan iklim mikro di Jalan Soekarno Hatta dipengaruhi oleh beberapa faktor, yaitu faktor suhu udara, kelembaban, angin dan penyinaran matahari. Hasil pengamatan menunjukkan bahwa suhu rata-rata di Jalan Soekarno Hatta $31.1^{\circ} \mathrm{C}$ dan rata-rata kelembapan $57 \%$. Nilai $\mathrm{THI}$ jalan tersebut berada diluar nilai kenyamanan THI yaitu 21-27. Suhu udara di Jalan Soekarno Hatta berkisar antara $29.1-42.4^{\circ} \mathrm{C}$ dan Nilai kelembaban untuk bagian ini berkisar dari 54.78-59.44\%. Jarak vegetasi di Jalan Soekarno Hatta 
mempengaruhi suhu udara maupun kelembaban. Pada area jalan yang jarak tanam pohonnya relatif tidak rapat, suhu udara cenderung lebih tinggi dan kelembaban lebih rendah. Sebaliknya pada daerah dengan jarak tanam pohon cukup rapat, suhu udara cenderung lebih rendah dan kelembaban menjadi lebih tinggi selain itu kondisi tajuk pohon-pohon penaung yang ada belum cukup dewasa sehingga kerapatan yang kurang turut mempengaruhi iklim mikro di Jalan Soekarno Hatta. Dari hasil THI ini maka perlu dilakukan penataan ulang lanskap jalan terutama dalam penataan vegetasi dengan kombinasi tanaman pohon, semak, perdu dan groundcover pada lanskap jalan. Pemilihan jenis vegetasi yang tepat merupakan faktor utama dalam meningkatkan kenyamanan termal serta kualitas fisik dan biofisik pada lanskap jalan. Dari Analisa persepsi tidak ada pengaruh antara hubungan kenyamanan dengan faktor jenis kelamin, tingkat pendidikan, tempat tinggal dan intensitas melewati jalan, mayoritas persepsi responden merasa cukup nyaman berada di jalan Soekarno Hatta

\section{Ucapan Terima Kasih}

Dengan terselesaikannya Karya IImiah ini, penulis mengucapkan terimakasih yang sedalam-dalamnya kepada:

1. Allah S.W.T. atas limpahan karunia dan hidayahnya sehingga penulis dapat melaksanakan penelitian dan menyelesaikan Karya Ilmiah.

2. Civitas akademika Universitas Tribhuwana Tunggadewi yang telah banyak mendukung dan memfasilitasi dalam pelaksanaan penlitian ini.

3. Lembaga Penelitian dan Pengabdian Masyarakat Universitas Tribhuwana Tunggadewi yang telah memberikan saran dan kritiknya hingga selesainya karya ilmiah ini.

4. Rekan-rekan dosen Program Studi Arsitektur Lanskap Fakultas Pertanian Universitas Tribhuwana Tunggadewi yang berperan aktif dalam pelaksanaan penelitian ini.

5. DRPM Kemristekdikti yang turut serta bertanggungjawab dan memfasilitasi secara teknis dalam kegiatan penelitian ini hingga penerbitan karya ilmiah

\section{Daftar Pustaka}

Alfian R. 2015. Pengaruh Bentuk Hutan Kota terhadap Kenyamanan Termal Di Sekitar Hutan Kota [Tesis]. Bogor (ID): Institut Pertanian Bogor

Alfian R, Setyabudi I, Uran R.S. 2016. Pengaruh Fungsi Vegetasi Pengaruh Fungsi Vegetasi terhadap Kenyamanan Termal Lanskap Jalan di Kawasan Kolonial Jalan Besar Idjen, Malang. Prosiding Seminar Nasional Temu IImiah IPLBI 2016. Institut Teknologi Nasional. Malang

Alfian R. 2016.Pengaruh Bentuk Hutan Kota Terhadap Kenyamanan Termal di Seitar Hutan Kota. Jurnal Buana Sains (16) No 2: 101-110.

Derartemen Pekerjaan Umum. 1980. Undang-Undang No. 13 Tentang Jalan. Departemen Pekerjaan Umum, Direktorat Jenderal Bina Marga. $29 \mathrm{p}$.

Direktorat Jenderal Bina Marga. 1996. Tata Cara Perencanaan Teknik lanskap Jalan. Departemen Pekerjaan Umum. Jakarta.

Forman, R.T.T., Alexander, L.E., 1998. Roads and Their Major Ecological Effects. Annu. Rev. Ecol. Evol. Syst. 29, 207-231.

Hadi, Rohman. 2012. Evaluasi Indeks Kenyamanan Taman Kota (Lapangan Puputan Bandung I Gusti Ngurah Made Agung Denpasar, Bali). E-Journal Agroekoteknologi Tropika Vol. 1 No. 1, Juli 2012. Fakultas Pertanian. Universitas Udayana

Humphreys dan Nicol. 2002. Adaptive Thermal Comfort and Sustainable Thermal Standards for Buildings, Energy and Buildings 34, Elsevier Science, [diunduh 2015 Agustus]. Tersedia pada: www.elsevier.com/locate/enbuild.

Isyani. 2006. Evaluasi Tanaman Bagi Pengembangan Lanskap Jalan Utama Kota Bumi, Lampung Utara [Tesis]. Bogor (ID): Institut Pertanian Bogor

Mo, Wembo, Yong Wang, Yingxue Zhang, Dafang Zuang. 2017. Impacts of road network expansion on landsape ecological risk in a megacity, China: A case Studi of Beijing. Science of the Total Env. 574: 1000-1011 
Nugroho M I. 2011. Valuasi manfaat ekologis kanopi pohon perkotaan dan ruang terbuka hijau Kota Malang dengan menggunakan teknik GIS [thesis]. Bogor (ID). Departemen Arsitektur Lanskap. Fakultas Pertanian Institut Pertanian Bogor.

Rahmiati, Mimi. 2009. Studi Aspek Kenyamanan Ruang Pedestrian Dalam Rangka Peningkatan Efektivitas Penggunaannya pada Kawasan Jalan M.H Thamrin- Jend.Sudirman, Jakarta. Tesis. Institut Pertanian Bogor

Santyo, Dwi. Ardiansyah P.Fahmi.Parmono. Harwin, Dwi. 2011. Kajian Aspek Kenyamanan pada Jalur Pedestrian di Penggal Jalan Prof. Soedharto Ngesrep (Patung Diponegoro-Gerbang Undip), Laporan Seminar, Universitas Diponegoro, Semarang

Setyowati S. 2012. Peran ruang terbuka sebagai ruang sosialisasi anak dalam membentuk karakter bangsa [Thesis]. Surakarta (ID): Program Studi Arsitektur. Fakultas Teknik Universitas Muhammadiyah Surakarta.

Simond J.O. 1978. Earthscape A Manual of Enviromental Planning. Mc GrawHill Co., New York. 340 p Talarosa B. 2005. Menciptakan kenyamanan termal dalam bangunan..Jurnal Sistem Teknik Industri. 6(3).

Unterman, Richard. 1984. The Pedestrian and The Bysiclist, 115 Fifth Avenue New York, NY United States 10003 